\title{
JURISPRUDENCIA EXTRANJERA COMENTADA RESPONSABILIDAD CIVIL MÉDICA
}

Rodrigo Míguez Núñez

Investigador en Derecho Privado

Universidad de Turín

UNA CAUSAL AUTÓNOMA

DE RESARCIMIENTO

EN LA RESPONSABILIDAD

CIVIL MÉDICA:

LA INFRACCIÓN AL DEBER

DE INFORMACIÓN

COMO VIOLACIÓN DEL DERECHO

A LA AUTODETERMINACIÓN

(Corte Suprema de Casación

ITALIANA 12 DE ENERO DE 2010)

La Casación italiana distingue la solicitud de indemnización que tiene por objeto el daño derivado de la violación del derecho del paciente a elegir cómo orientarse en el ámbito de las opciones terapéuticas, de aquél relativo a la salud causalmente asociado al defecto de información. El primero es un daño de naturaleza no patrimonial, derivado de la violación del derecho a la autodeterminación del paciente e indemnizable cuando el interés tutelado sea afectado más allá del límite establecido por el principio de la tolerancia y el parámetro estatuido por la conciencia social en un determinado momento. El segundo se verifica toda vez que el enfermo acredite que, informados los riesgos derivados de la ejecución de la intervención quirúrgica, la habría rechazado.

\section{CONSIDERACIONES INTRODUCTIVAS:}

EL PRINCIPIO Y SUS FUENTES

Las preocupaciones ético-jurídicas que se acuñan en torno a la delicada relación entre poder, medicina y paciente han permitido que el principio del consentimiento informado represente en nuestros días una máxima de la libertad y de la dignidad personal. La cura del paciente, además de incidir en su salud, trasciende a su estatuto jurídico y moral, comprendiendo diversos aspectos de su personalidad. No se trata entonces de preocupaciones infundadas, sino de premisas que nos recuerdan el ejercicio de una medicina desvincu- 
lada de la moral, del derecho y del compromiso con el bienestar físico y síquico del enfermo. Es por tal motivo que el análisis de los antecedentes modernos del principio relaciona oscuros momentos de nuestra historia contemporánea referentes a las violaciones de los derechos humanos generados durante las más recientes experiencias bélicas y experimentos con seres humanos. De hecho, todo miramiento históricojurídico relativo a los orígenes del consentimiento informado debe abordar el examen de dos importantes textos relativos al aspecto ético de la investigación con seres humanos gestados como consecuencia de las atrocidades cometidas en nombre de la experimentación médica por el régimen nazi: el Código de Nuremberg (1947) y la posterior Declaración de Helsinki de la Asociación Médica Mundial $(1964)^{1}$. Con ellos, se estatuye el principio del respeto al individuo, a su autodeterminación y a la toma de decisiones informadas. Más tarde, el Pacto Internacional de Derechos Civiles y Políticos, en vigor desde 1976, precisará en su artículo 7:

"Nadie será sometido a torturas ni a penas o tratos crueles, inhumanos o degradantes. En particular, nadie será so-

\footnotetext{
${ }^{1}$ Secundada por la Declaración de Lisboa sobre los Derechos del Paciente, adoptada por la 34ª Asamblea Médica Mundial en 1981 y enmendada por la $47^{\mathrm{a}}$ Asamblea General de Bali en 1995.
}

metido sin su libre consentimiento a experimentos médicos o científicos".

Desde luego, no todos los abusos médicos que motivaron la afirmación del principio deben situarse en acontecimientos bélicos.

Notable es el caso del estudio sobre la sífilis no tratada en la población masculina negra de Tuskegee (Alabama), experimento clínico realizado por el United States Public Health Service entre 1932-1972 con el objetivo de verificar los efectos del progreso de la enfermedad en un cuerpo infectado no tratado, aun cuando, ya a partir de 1940, la eficacia de la penicilina en la enfermedad se encontraba del todo comprobada.

Para remediar el escándalo se aprobó en 1974 la National Research Act (Publ. L. 93-348), normativa destinada a regular la experimentación humana en Estados Unidos.

Experiencias de este tipo se repiten en la historia, pues las circunstancias que evidencian la necesidad del principio y el frágil escenario ético-jurídico donde éste se mueve generan controversia en todo tiempo y latitud ${ }^{2}$.

En la casuística europea, ya a partir de la década de 1940 se desarrolla el postulado que condiciona la licitud del tratamiento médico

${ }^{2}$ Véase George J. Annas, "Globalized Clinical Trials and Informed Consent", in The New England Journal of Medicine, $\mathrm{N}^{\mathrm{o}} 360$, Waltham, MA, 2009, pp. 2.050-2.053. 
al consentimiento informado del asistido. Así, el Reichsgericht declaró en 1940 la responsabilidad de un médico que, habiendo extraído un quiste del pecho de una paciente, omitió (para no impresionarla) el hecho que la operación comportaba la oblación del seno ${ }^{3}$.

Símil solución fue adoptada en 1942 por la Corte de Casación francesa en el histórico caso Teyssier, donde se recalcó el principio

"de obtener el consentimiento del enfermo antes de practicar una operación"

en virtud del "respeto de la persona humana".

Por su parte, una trascendental contribución en la materia ha correspondido a la normativa europea contemporánea.

El Consejo de Europa adoptó en Oviedo, el 4 de abril de 1997, la Convención para la Protección de los Derechos Humanos y de la Dignidad del Ser Humano con respecto a las aplicaciones de la Biología y la Medicina. Su art. 5 estableció la siguiente regla general:

"No podrá llevarse a cabo intervención alguna sobre una persona en materia de salud sin su consentimiento infor-

${ }^{3}$ RG, 8 de marzo de 1940, en Entscheidungen des reichsgerights in zivilsachen, $\mathrm{N}^{\circ} 163$, Leipzig, 1940, p. 129.

${ }^{4}$ Cass. req., 28 de enero de 1942, en Dalloz: recueil critique, 1942, jurispr. 63. mado y libre. Dicha persona recibirá previamente una información adecuada sobre la finalidad y naturaleza de la intervención, así como de sus consecuencias y riesgos. La persona afectada, podrá retirar su consentimiento en todo momento y con entera libertad"5.

Otro instrumento garante emana de la reciente Carta de Derechos Fundamentales de la Unión Europea. El texto, en vigor como documento vinculante del tratado de Lisboa desde el 1 de diciembre de 2009, declara en su art. 1 que la dignidad humana es inviolable y que será respetada y protegida.

Junto al derecho a la vida (art. 2), la Carta salvaguarda el derecho a la integridad física y síquica (art. 3, $\mathrm{N}^{\mathrm{O}}$ 1), mientras que en el ámbito de la Medicina y de la Biología se respeta

"el consentimiento libre e informado de la persona de que se trate, de acuerdo con las modalidades establecidas en la ley" (art. 3, No 2$)^{6}$.

En Italia, el consentimiento informado representa uno de los grandes temas del debate jurídico actual en el ámbito de la responsabilidad civil

${ }^{5}$ Véase texto en http://www.sibi.org/ pub/conv.htm, consultado el 19 de julio de 2010.

${ }^{6}$ Texto íntegro en http://www.europarl. europa.eu/charter/default_es.htm, visitado el 20 julio de 2010. 
médica ${ }^{7}$. La legislación internacional

${ }^{7}$ Para una primera aproximación véase Renato BALduzzi y Davide PARIS, "Corte costituzionale e consenso informato tra diritti fondamentali e ripartizione delle competenze legislative", in Giurisprudenza Costituzionale, No 6, Milano, 2008, pp. 4.953-4.970; Simona CACACE, "Informazione, consenso e rifiuto delle cure", in Giovanni Comandé (ed.), Diritto privato europeo e diritti fondamentali. Saggi e ricerche, Torino, Giappichelli, 2004, p. 77 ss.; Carlo Casonato, "Consenso e rifiuto delle cure in una recente sentenza della Cassazione", in Quaderni costituzionali, No 3, Bologna, 2008, pp. 545-576; Giovanni FACCI, "Brevi osservazioni in tema di funzione riparatoria della responsabilità civile e violazione del sanitario del dovere di informazione", in Responsabilità Civile e Previdenza, $\mathrm{N}^{\circ}$ 2, Milano, 2008, pp. 408421; Gilda Ferrando, "Consenso informato del paziente e responsabilità del medico. 308 Principi, problemi e linee di tendenza", in Studi in onore di Pietro Rescigno, vol. v, Milano, Giuffrè, 1998, p. 201 ss.; Alessandra Mastrolitto, "Consenso informato del paziente e responsabilità' professionale del medico", in Annali della Facoltà di Giurisprudenza di Foggia, Milano, Giuffrè, 2005, p. 407 ss.; Gianluca Montanari VerGALlO, Il rapporto medico-paziente, Milano, Giuffrè, 2008; Ubaldo Nannini, Il consenso al trattamento medico: presupposti teorici e applicazioni giurisprudenziali in Francia in Germania, Milano, Giuffrè, 1989; Amadeo Santosuosso (ed.), Il consenso informato. Tra giustificazione per il medico e diritto del paziente, Milano, Raffaello Cortina Editore, 1996; Nicola Todeschini, "Responsabilità professionale e dovere d'informazione: dal consenso disinformato al dovere contrattuale di informare", in Cosimo LoRÉ (ed.), Tra scienza e società, Milano, Giuffré, p. 295 ss.; Giovanni Toscano, Informazione, consenso $e$ responsabilità sanitaria, Milano, Giuffrè, 2006; Marco Trabucchi, L'ammalato e il suo medico: successi e limiti di una relazione, Bologna, il Mulino, 2009; Paolo ZatTI, Maschere del diritto y comunitaria, con la sola excepción de la convención de Oviedo (cuerpo, sin embargo, recurrible como auxilio hermenéutico respecto al Derecho interno) constituye el sólido piso normativo en la materia.

Diverso es el escenario de la legislación interna. El cuadro de las fuentes es de hecho bastante difuso. A diferencia de países como Francia ${ }^{8}$ o España ${ }^{9}$, donde el consentimiento informado ha sido reglamentado en términos generales, el legislador italiano opta por un tratamiento fragmentario y parcial. En el ámbito

volti della vita, Milano, Giuffrè, 2009. Para el más actualizado estado de la cuestión véase Michele Graziadei, "Il consenzo informato e i sudi limiti" in I Diritti in medicina, a cargo de Leonardo Lenti, Elizabetta Palermo Fabris, Paolo Zatti, in Trattato di biodiritto, dirigido por Stefano Rodotà y Paolo ZatTI, Milano, Giuffrè, 2011, pp. 191-288; Michele GraziadeI, "What went worong? Tort law, personal responsibility, expectations of proper care and compensation", in Helmut Koziol y Barbara C. Steininger (eds.), European Tort Law 2008, Wien, Springer, 2009, pp. 2-24; Edwoud Hondius, "The development of medical liability", in John Bell and David Ibbetson (eds.), Comparative studies in the development of the law of torts in Europe, Cambridge, Cambridge University Press, 2010, vol. 3; Edwoud Hondius, "Comparative Medical Liability in Europe", in Festschrift für Hans Stoll zum 75. Geburtstag, Tübingen, Mohr, 2001, p. 185 ss.

${ }^{8}$ Se trata de la ley $\mathrm{N}^{\circ} 2002-303$ de 4 de marzo de 2002, relative aux droits des malades et à la qualité du système de santé.

${ }^{9}$ Ley $41 / 2002$, de 14 de noviembre de 2002, Básica Reguladora de la Autonomía del Paciente y de Derechos y Obligaciones en Materia de Información y Documentación Clínica. 
constitucional, el art. 32 garantiza la salud como derecho fundamental y prohíbe tratamientos sanitarios obligatorios (salvo en los casos previstos por la ley y siempre que ello no comporte una afrenta a la dignidad humana). Por su parte, el art. 13 establece el principio de la inviolabilidad de la libertad personal. Ambas normas se conectan con lo estatuido por el art. 2 sobre el reconocimiento y garantía de los derechos inviolables del hombre. Sobre la base de estas disposiciones, la Corte Costituzionale ha señalado en reiteradas ocasiones que el consentimiento informado representa un derecho de la persona reconocido constitucionalmente $^{10}$.

En la misma línea, la Corte Suprema di Cassazione (en adelante "la Corte" o "la Casación") ha sostenido que la inobservancia del requisito del consentimiento libre e informado representa un ilícito, sin importar la oportunidad, procedencia o éxito de la prestación médica, pues éste constituye

"una forma de respeto de la libertad del individuo y un medio para el perseguimiento de sus mejores intereses"11.

${ }^{10}$ Corte Constitucional 23 diciembre 2008, N ${ }^{\circ} 438$, in Foro Italiano, $\mathrm{N}^{\circ} 5$, parte I, Bologna, 2009, p. 1.328.

${ }^{11}$ Cass. civ., sez. III, 16 de noviembre de $2007, N^{\circ} 21748$, in Foro Italiano, $\mathrm{N}^{\circ} 11$, parte I, Bologna, 2008, p. 3.025; Cass. civ., sez. III, 14 marzo $2006, \mathrm{~N}^{\circ} 5444$.
Al igual que en $\mathrm{Chile}^{12}$, la legislación italiana no trata el consentimiento informado en forma general. En lo tocante a la legislación sanitaria, ciertas leyes, como la relativa a las inspecciones y tratamientos sanitarios voluntarios y obligatorios ( $\mathrm{N}^{\mathrm{O}}$ 180/1978) o la que instituyó el Servicio Sanitario Nacional $\left(\mathrm{N}^{\mathrm{o}}\right.$

${ }^{12}$ En Chile, sin perjuicio de la normativa constitucional recurrible, se suele citar como norma general en la materia el art. 34 del decreto $\mathrm{N}^{\circ} 140$, que contiene el Reglamento Orgánico de los Servicios de Salud (21 de octubre de 2005). Asimismo, una serie de normas sectoriales regulan cada vez con mayor frecuencia diversos aspectos del consentimiento informado. La ley No 20.120 de 2006, sobre la Investigación Científica en el Ser Humano, su Genoma, y Prohíbe la clonación humana, condiciona toda actividad científica en el ser humano al consentimiento, previo e informado (arts. 9, 11). El Reglamento Sanitario Internacional (OMS 2005), promulgado el 5 de septiembre 2008 por el Ministerio de Relaciones exteriores (Diario Oficial, 23 de diciembre de 2008) se refiere al principio al tratar las medidas sanitarias al ingreso y salida del país (art. $23 \mathrm{~N}^{\circ} 3$ ). Es, además, interesante el tratamiento sectorial del principio conferido por un conjunto de recientes decretos del Ministerio de Salud en materias relativas a la homeopatía (decreto $N^{\circ} 19$, Diario Oficial, 16 de marzo de 2010), centros de tratamiento y rehabilitación de personas con consumo perjudicial o dependencia a alcohol y drogas (decreto $\mathrm{N}^{\mathrm{o}} 4$, Diario Oficial, 13 de enero de 2010); acupuntura (decreto $\mathrm{N}^{\mathrm{O}} 123$, Diario Oficial, 26 de mayo de 2008) y uso de productos farmacéuticos sin registro sanitario para fines de investigación científica (circular No 4, Diario Oficial, 5 de septiembre de 2009). Una tratativa general del consentimiento informado reposa en el art. 16 del proyecto de ley sobre los derechos y deberes de las personas en salud (2001). 
833/1978), abordan el principio en forma incidental. Asimismo, normas sectoriales y de rango inferior (como líneas guías formuladas por entes regionales para organizar la actividad sanitaria local) han desarrollado, con relativo detalle, alcances específicos del principio. Merece también atención el tratamiento dispuesto por del Código Deontológico de la Profesión Medica de $2006^{13}$ que, aunque de escaso valor legal, constituye sin duda un elemento de integración para la legislación civil.

\section{EL CASO EN EXAMEN}

En febrero de 1993 una mujer demandó en juicio indemnizatorio a 310 su médico oftalmólogo, quien el 18 de febrero de 1991 la sometió a una intervención quirúrgica de catarata extirpándole el cristalino del ojo derecho. Solicita la actora la condena al resarcimiento de los daños por las complicaciones (queratitis corneal bullosa, para cuya remoción fue necesario realizar un ulterior transplante de cornea) no debidamente informadas por el facultativo como riesgos inherentes a la cirugía y que se generaron a consecuencia de la misma. En su pronunciamiento $\mathrm{N}^{\mathrm{O}}$ 2095 de 2002, el Tribunal de Nápoles rechazó en primera instancia

${ }^{13}$ Es común que normas sobre consentimiento informado se incluyan en los códigos que regulan profesiones relativas a la salud. En Chile, véase el art. 25 del Código de Ética del Colegio Médico, 2008. la demanda. El juez estimó que la intervención era necesaria y que ésta fue realizada en forma correcta, respetando las normas propias de la ciencia médica. Respecto a la falta de consentimiento informado, se dispuso que debió haber sido probado por la paciente y que tal prueba no fue aportada $^{14}$. Conociendo en recurso de apelación, la Corte de Nápoles, en resolución $\mathrm{N}^{\mathrm{o}} 242$ de 2005, revocó la sentencia afirmando que no habiendo el médico, sobre quien incumbía la carga probatoria de la presencia del consentimiento informado, ni afirmado, ni probado de haber informado a la asistida sobre los riesgos previsibles de la intervención y de haber recibido el consentimiento de ella, procede declarar la responsabilidad del facultativo por los daños derivados de la intervención realizada sin el indicado consentimiento, no teniendo ninguna relevancia la circunstancia de haber realizado la intervención en forma correcta. La sentencia de segunda instancia declaró la responsabilidad del médico por la falta de consentimiento informado condenándolo al resarcimiento de los daños sufridos por la paciente

${ }^{14}$ Es la solución dominante en jurisprudencia italiana de los años noventa. Ella confería al paciente la carga del peso de la prueba de la falta -o del imperfecto- cumplimiento del deber de información por parte del facultativo. Véase Cass. civ., 29 de enero de 1993, No 1119, in Foro Italiano, parte. I, Bologna, 1993, p. 1.469; Cass. civ., 25 de noviembre de 1994, $\mathrm{N}^{\mathrm{O}}$ 10014; Cass. civ., 6 de octubre de 1997, No 9705; Cass. civ., 9 de enero de $1997, \mathrm{~N}^{\circ} 124$. 
en razón de la invalidez temporal, de la queratopatía bullosa y por los gastos afrontados en virtud del sucesivo trasplante de córnea necesario para remediar la patología surgida. La Corte liquidó el daño en €74.040 más costas. El médico recurrió de casación. Con fecha 12 de enero de 2010, la Corte Suprema rechazó el recurso ${ }^{15}$.

El caso enunciado plantea, en breve, un tema que ha motivado la atención de estudios chilenos y extranjeros por su frecuencia ${ }^{16}$. Se trata

${ }^{15}$ Cass. civ., sez. III, 12 de enero de 2010 (depositada el 9 de enero de 2010), $\mathrm{N}^{\mathrm{O}}$ 2847, presidente Mario Rosario Morelli, Alfonso Amatucci, in Guida al diritto, $\mathrm{N}^{\mathrm{O}}$ 9, Roma, 2010, p. 75 ss. (cheratite bollosa insorta in seguito ad operazione di cataratta). Pueden consultarse los primeros comentarios en Angelo Riccio, "La violazione dell'autodeterminazione è, dunque, autonomamente risarcibile", in Contratto $e$ impressa, No 2, Padova, 2010, pp. 313-322; con referencias críticas Patrizia ZIvız, "I labili confini dell'ingiustizia costituzionalmente qualificata", in Responsabilità Civile e Previdenza, $\mathrm{N}^{\mathrm{o}} 4$, Milano, 2010, pp. 788-797; Marinela Gorgoni, "Ancora dubbi sul danno risarcibile a seguito di violazione dell'obbligo di informazione gravante sul sanitario", in Responsabilità Civile e Previdenza, $\mathrm{N}^{\circ} 5, \mathrm{~Pa}-$ dova, 2010, pp. 1.014-1.026.

${ }^{16}$ Véase, en lo específico, Iñigo DE LA Maza Gazmuri, "Consentimiento informado y relación de causalidad", en Iñigo DE LA Maza Gazmuri (comp.), Cuadernos de Análisis Jurídico, Santiago, Ediciones Universidad Diego Portales, Colección de Derecho Privado, 2010, vol. vi, pp. 127-143; María Paz García Rubio, "Incumplimiento del deber de información, relación de causalidad y daño en la responsabilidad civil médica", en Eugenio Llamas Poмbo (coord.), Estudios de derecho de obligaciones. Homenaje al profesor Mariano Alonso de resolver la compleja situación en la cual existiendo incumplimiento del deber de informar por parte del facultativo y cumpliendo éste con las exigencias de la lex artis, se producen, sin embargo, resultados perjudiciales y previsibles para la salud del enfermo asociados al riesgo de la actuación médica.

\section{EL RECURSO \\ Y FUNDAMENTOS DEL FALLO}

El recurso deducido se basa en cuatro motivos:

- El primero denuncia la aplicación indebida de los arts. 1337, 2697 y 2043 del $C C$ en materia de onus probandi. Para el recurrente el tribunal de segunda instancia ha violado dichas normas al disponer que el peso de la prueba del consentimiento informado correspondía al médico. En sostén, señala que el consentimiento del paciente es inherente a la fase que precede al contrato de prestación de obra profesional por lo que se trataría de una hipótesis de responsabilidad precontractual que, por encontrarse tradicionalmente encuadrada en el seno de la

Pérez, Madrid, La Ley, 2006, tomo I, pp. 801827; Riccardo CAMPIONE, "Trattamento medico eseguito lege artis in difetto di consenso: la svolta delle S.U. penali nella prospettiva civilistica", in La Responsabilità Civile, $\mathrm{N}^{\circ} 11$, Torino, 2009, pp. 881-898. 
responsabilidad aquiliana, debe gobernarse por la regla según la cual la prueba del hecho ilícito corresponde al acreedor. La Casación desestima el motivo del recurso al considerar que la intervención del médico, aún en su función diagnóstica, instituye una relación contractual. De ello, afirma la Corte, se deduce que efectuado el diagnóstico en ejecución del contrato, la ilustración de las consecuencias (ciertas o inciertas) de la terapia que el médico considera forzosas u oportunas al fin de obtener el necesario consentimiento para la ejecución de la prestación terapéutica, constituye una obligación cuyo incumplimiento debe probarse por la parte que incumpe, esto es, por el médico, en razón de la alegación de incumplimiento de la contraparte.

- El segundo motivo ataca el fundamento de la sentencia relativo a la supuesta previsibilidad de la patología corneal surgida de la intervención quirúrgica. Se afirma que de la prueba e informe rendidos en autos ella no resulta apoyada en argumentos sólidos e idóneos, evidenciándose una supuesta discordancia entre las pericias médicas relativas a la previsibilidad de la queratitis. Tampoco este motivo es acogido por la Casación, pues existe en su opinión coherencia en los peritajes recibidos y un correcto valor probatorio conferido a éstos y a las demás pruebas por el juez de instancia.

Es nuestro interés destacar la argumentación planteada en los motivos tercero y cuarto del recurso. Ellos invitan a la Corte a reflexionar sobre la violación de la obligación de información y acerca de los efectos que ello conlleva en temáticas relativas al nexo de causalidad, daños reparables, y contenido y distribución del peso de la prueba. Enunciemos el razonamiento deducido para luego profundizar en sede separada.

- El tercer motivo casa la sentencia por indebida aplicación del art. 1223 y ss. del $C C$ (concernientes a los criterios de determinación de los daños indemnizables) y por vicios de motivación del fallo en aspectos decisivos. Para el recurrente, establecida la ausencia de culpa profesional en la ejecución de la intervención quirúrgica de extirpación de la catarata, la condena a la indemnización por los sufrimientos y grandes gastos derivados de la queratitis bullosa, comporta imputarle tal patología, en circunstancias que siendo al médico adscrita la sola violación de su obligación de 
información, no pueden ser consideradas a fin resarcitorio las consecuencias de la lesión del derecho a la salud, sino, a lo sumo, sólo aquellas asociadas a la lesión del

"diverso y autónomo derecho a la libre y consciente autodeterminación del paciente sobre el someterse o no a la intervención",

sobre la base de lo establecido por los artículos 2, 13, 32 de la Constitución. Para atribuirle las consecuencias negativas de la intervención, necesaria y correctamente ejecutada, el recurrente señala que debería arribarse a la conclusión de que la paciente no se habría sometido a la intervención si hubiese sido informada, no pudiendo de otro modo afirmarse la existencia del nexo de causalidad entre la violación (información omitida) y el bien jurídico protegido (la salud). Tal indagación, agrega, no fue realizada y si lo hubiese sido, la indiscutible necesidad de la intervención habría inducido a la Corte de Apelaciones a la conclusión de que la mujer se habría sometido a la operación aun siendo adecuadamente informada.

El último motivo denuncia la indebida aplicación de los artículos 185 del $C P$ y 1223 ss. del $C C$ en relación con los numerandos $3^{\circ}$ y $5^{\circ}$ del art.
360 del $C P C$ por haberse liquidado, juntamente con otros daños (biológico por invalidez temporánea y patrimonial) el daño moral, atendidos los sufrimientos padecidos por el paciente como consecuencia de la aparición de la queratitis bullosa y de la sucesiva intervención quirúrgica. El recurrente afirma que el daño moral subjetivo puede ser reconocido sólo en presencia de una figura delictual, en la especie inexistente. Agrega que la ausencia de nexo causal entre la violación del deber de información y la queratopatía bullosa manifestada luego de la intervención (de la cual surgieron los sufrimientos padecidos por la asistida) permite colegir una solución contraria a la sostenida por Corte de Apelaciones sobre la base de las razones indicadas en el tercer motivo del recurso.

Se aprecia que la cuestión fundamental planteada reside en elucidar la posibilidad de vincular en modo causal la falta de información al resultado en la salud del paciente como, asimismo, la fijación de los daños indemnizables. Las pretensiones deducidas en los últimos motivos resultan rechazadas atendidos los fundamentos que pasamos a comentar.

\section{Nexo de causalidad}

La disyuntiva principal a la que se enfrenta la tercera sección civil de la Casación italiana es la siguiente:

a) debe el médico responder de las consecuencias perjudiciales para la salud del paciente derivadas de una inter- 
vención quirúrgica necesaria y correctamente efectuada por el sólo hecho de no haber informado la posibilidad que aquellas consecuencias se verifiquen;

b) o si para que sean resarcibles debe afirmarse y acreditarse que el paciente no se habría sometido a la intervención si hubiese sido oportunamente informado.

Ante todo, debe revelarse que la Casación ha reiterado en numerosas ocasiones que

"la omisión de la solicitud del consentimiento constituye fuente autónoma de responsabilidad en el caso que de la intervención deriven efectos lesivos, o incluso mortales, para el paciente, por lo que ninguna importancia puede tener el hecho que la intervención misma haya sido realizada en modo correcto" ${ }^{17}$.

De ahí que la sentencia en examen declare:

"en defecto del consentimiento informado de parte del paciente,

${ }^{17}$ Cass. 26 de marzo de 1981, No 1773 , en Archivio civile, 1981, p. 544; Cass. sez. III, 6 de octubre de 1997, No 9705, en Giurisprudenza Italiana, Torino, 1998, p. 1816; Cass., sez. III, 24 de septiembre de 1997, N $^{\circ} 9374$, en $L a$ Responsabilità Civile e Previdenza, $\mathrm{N}^{\mathrm{o}} 1$, Milano, 1998, p. 78; Cass. sez. III, 14 de marzo de 2006, N ${ }^{\mathrm{O}}$ 5444, en Giurisprudenza Italiana, $\mathrm{N}^{\mathrm{O}}$ I, Torino, 2007, p. 343.

la intervención terapéutica constituye un ilícito y por consiguiente el médico responde de las consecuencias negativas que deriven aun cuando haya realizado correctamente la prestación".

Como lo señalamos, las normas que gobiernan el nexo de causalidad civil son invocadas por el facultativo para negar que el daño producido al paciente sea asociable a la violación de las normas de consentimiento informado, ya que éste se habría producido aun cuando el enfermo hubiese consentido. Es posible conjeturar afirmando que, ponderados los costos y beneficios, el paciente se habría sometido a la intervención aun siendo sido informado de los riesgos asociados a ella. La sentencia, en efecto, hipotetiza sobre el consentimiento del asistido añadiendo el comportamiento omitido y declarando que si el facultativo hubiese informado y al momento de la intervención el paciente hubiese consentido, sería evidente la inexistencia del nexo de causalidad material entre el comportamiento omisivo del médico y la lesión de la salud del enfermo, pues éste habría sufrido el perjuicio en todo caso. Por tal razón, pareciera imponerse una conclusión: entre la violación de la obligación de operar con el consentimiento informado del paciente y el perjuicio sufrido por éste no existiría el nexo de causalidad necesario para establecer la responsabilidad médica. La causalidad se rechaza, pues la salud del paciente 
habría sido en todo caso perjudicada, ya por el progreso de la patología, ya por verificarse los riesgos asociados a ella en el caso de no tratarse, ya en el caso de someterse al tratamiento recomendado -aun conociendo todos los riesgos- como lo habría hecho el si hubiese sido adecuadamente informado $^{18}$. El daño sufrido sería, por consiguiente, inevitable $y$, por lo mismo, no resarcible.

Sobre la base de estas consideraciones, una discutida sentencia de la Corte de Casación francesa de 2007 rechazó la responsabilidad médica por el daño sufrido a raíz de la violación de la obligación de información, estableciendo que el único perjuicio reparable como consecuencia del incumplimiento es

"la perdida de la posibilidad de escapar al riesgo que efectivamente se produjo" 19 .

${ }^{18}$ Graziadei, "Il consenzo..." n. 7.

${ }^{19} \mathrm{El}$ contencioso surgió a raíz de una intervención quirúrgica solicitada por el paciente para remover una estenosis trombótica a cargo de la carótida interior derecha. La operación (apreciada por los expertos como no urgente) dejó al enfermo en estado hemipléjico, complicación conocida, pero de rara ocurrencia, y sin embargo omitida al paciente. Véase Cass. civ. $1^{\text {re }}, 6$ de diciembre de 2007, Consorts Larénaudie c. Aguilar et autres, No 06-19.301, en Dalloz, No 3, Paris, 2008, p. 192 ss., con nota de Pierre Sargos. Véanse, además, comentarios de Jean Hauser en $R T D$ civ., 2008, $\mathrm{N}^{\mathrm{o}}$ 2, Paris, p. $272 \mathrm{y}$ de Patrice Jourdain, RTD civ., 2008, $\mathrm{N}^{\circ} 2$, Paris, p. 303 ss. La solución adoptada por la Corte francesa pareciera corresponder a la opinión dominante en la doctrina chilena que ve en la infracción la perdida de la mera
El criterio asentado por la Corte francesa, blanco de duras críticas por la doctrina que sitúa el perjuicio moral sufrido por el paciente en el nicho de los derechos de la persona de estampa constitucional, ha sido objeto de un reciente e histórico revirement. En un pronunciamiento de junio del presente año, la Casación francesa ha desechado la tesis sostenida por el médico (quien arguyó que la intervención, cuyos riesgos no se informaron, no tenía alternativa dado el riesgo de graves infecciones al que se encontraba expuesto el asistido), reconociendo en la violación del derecho de informar un atentado a la dignidad humana. Sobre dicha base, la Corte dispuso que la falta de información constituye un hecho capaz de generar por si mismo un perjuicio moral que debe ser indemnizado ${ }^{20}$.

"posibilidad" u "opción" de someterse o no al tratamiento. Véase Carlos Pizarro Wilson, "Responsabilidad profesional medica: diagnóstico y perspectivas", en Cuadernos de Análisis Jurídico, Santiago, Ediciones Universidad Diego Portales, Colección de Derecho Privado, 2008, vol. IV, p. 176.

${ }^{20}$ El médico realizó una adenomectomía prostática sin informar previamente al paciente sobre el grave riesgo de impotencia inherente a la intervención, albur que se concretó. El tribunal de segunda instancia, rechazando toda indemnización, estimó que dada la patología padecida por el enfermo y la ausencia de alternativa terapéutica, éste habría aceptado la operación, aun cuando se le hubiese informado el riesgo de impotencia. Cass. civ., $1^{\text {re }}, 3$ de junio de 2010, No 09-13.591, en Recueil Dalloz, No 24 , Paris, 2010, con nota de Pierre Sargos, "Deux arrêts 'historiques' en matière de responsabilité médicale générale 
Regresando a nuestro escenario, nos percataremos que el razonamiento de la Corte francesa no es asilado. Con meses de antelación la Casación italiana sostuvo una similar doctrina en el fallo que comentamos. Así, para vislumbrar el problema de la causalidad la Corte declara que la existencia del nexo etiológico

"no debe indagarse sólo en relación al nexo de consecuencialidad entre la intervención terapéutica (necesaria y correctamente realizada) y el perjuicio a la salud",

sino

"en la relación entre la actividad omisiva del médico paciente y la ejecución de la intervención".

et de responsabilité particulière liée au manquement d'un médecin à son devoir d'information", pp. 1522-1526. El criterio de la Casación francesa se aúna al adoptado en el año 2004 por la Cámara de los Lores en una sentencia que contiene una incisiva posición a favor de la tutela de la autonomía del paciente y de su derecho a informarse sobre el riesgo al cual se encuentra expuesto por efecto de un tratamiento sanitario. En el caso Chester v. Afchar, 2004, UKHL 41, la Cámara se ha centrado en el 'right of autonomy and dignity' del paciente claramente formulado en términos de policy: “...I am glad to have arrived at the conclusion that the patient is entitled in law to succeed. This result is in accord with one of the most basic aspirations of the law, namely to right wrongs. Moreover, the decision announced by the House today reflects the reasonable expectations of the public in contemporary society".

Por ello, la reducción del problema a que el médico deba responder por las consecuencias negativas sufridas por el paciente que no prestó su consentimiento al ser ilícita la actividad medica así ejecutada, constituiría una

“simplificación priva del necesario miramiento a la real magnitud de la cuestión pues ésta no atañe tanto a la licitud de la intervención sino que nace de la violación del derecho a la autodeterminación del paciente, siendo al médico ante todo imputable por no haberlo adecuadamente informado para adoptar el preventivo y consciente consentimiento".

Recapitulando, hay lugar al resarcimiento cuando que la conducta omisiva del médico comporte una violación del derecho a la autodeterminación, derivando de ello consecuencias perjudiciales para el enfermo. Pero el problema de la causalidad no resulta del todo resuelto, ya que nos encontramos en un escenario donde las consecuencias perjudiciales de la omisión se relacionan estrechamente con el estado de salud del paciente. En esta dimensión, la lesión del derecho del consentimiento informado dará lugar a la tutela resarcitoria sólo cuando se acredite que ella es el antecedente causal de las elecciones (o de las privadas elecciones) que producen consecuencias perjudiciales al titular en la esfera de su salud. 
Pues bien, para resolver la causalidad relativa al daño a la salud la Corte señala que es necesario preguntarse, como en toda valoración hipotética, si la conducta omitida habría evitado el evento, es decir, si el cumplimiento de parte del médico de sus deberes informativos habría producido el efecto de la no ejecución de la intervención quirúrgica de la cual, sin culpa alguna, derivó el estado patológico del paciente. Dado que la intervención quirúrgica no se habría realizado si el asistido la hubiere rechazado, para verificar la existencia del nexo causal entre la lesión al derecho de autodeterminación (a raíz de la omisión de información de parte del médico) y la lesión a la salud por las -no culpables- consecuencias negativas de la intervención, debería aseverarse que el paciente habría rechazado la intervención, si hubiere sido informado, pues de otro modo (consintiendo) la conducta positiva omitida por el médico (información al fin de adquirir un consciente consentimiento) no habría evitado el evento (lesión a la salud). En síntesis, para la Casación existe causalidad en relación con el daño a la salud siempre y cuando pueda afirmarse que el paciente -oportunamente informado- habría rechazado la intervención.

Resta todavía resolver un cardinal aspecto del contencioso, ¿̇uáles son, entonces, las implicancias del daño derivado de la violación del derecho a la autodeterminación en cuanto bien jurídico diverso y autónomo respecto a la salud?

\section{La lesión del derecho a la autodeterminación \\ y sus consecuencias}

La Casación afirma, siguiendo el tenor de una serie de pronunciamientos previos, que el derecho a la autodeterminación es diverso del derecho a la salud ${ }^{21}$. El derecho a la autodeterminación representa

"una forma de respeto de la libertad del individuo y un medio para el perseguimiento de sus mejores intereses, que se sustancia no sólo en la facultad de elegir entre las diversas posibilidades de tratamiento médico, sino también en la facultad de rechazar la terapia y de decidir conscientemente de interrumpirla dado el principio personalista que anima nuestra Constitución, la cual ve en la persona humana un valor ético en sí, sancionándole el respeto en cualquier momento de su vida y en la integridad de su ser, en consideración al fajo de convicciones éticas, religiosas, culturales y filosóficas que orientan sus determinaciones volitivas"22.

Cierto es que la Casación construye su razonamiento sirviéndose de la

${ }^{21}$ Véase Cass. sez. III, 11 de mayo de 2009, No 10741; Cass., sez. III, 3 de marzo de $2007 \mathrm{~N}^{\mathrm{o}} 18513$ y de reciente, Cass. civ., 4 de enero de 2010, $\mathrm{N}^{\circ} 13$.

${ }^{22}$ Cass., sez. I, 16 de octubre de 2007, No 21748, con comentario de Casonato (n. 7). 
doctrina de la Corte Constitucional que ve en el consentimiento informado la presencia de un verdadero y propio derecho de la persona según lo prescrito en los arts. 2, 13 y 32 de la Constitución ${ }^{23}$.

En el terreno indemnizatorio, es preciso advertir que la doctrina que antecede al fallo, en examen, condicionaba la indemnización por el daño de no haber informado a dos tipos de hipótesis: si la intervención no consentida era indispensable para la salud del paciente o, bien, si ella tenía un resultado favorable. En la primera clase de hipótesis, siendo la intervención indispensable para la salud del enfermo, se volvía a distinguir si ella era realizada en forma correcta o no. La tendencia consistía en rechazar la indemnización en aquellos casos donde la intervención necesaria para el paciente, pero carente de su consentimiento informado, hubiese sido realizada en forma correcta. En el segundo tipo de hipótesis se analizaba, en cambio, la naturaleza positiva o negativa de las consecuencias de la intervención no consentida. En caso de mejoramiento de las condiciones de salud no existía algún daño a resarcir. En caso desfavorable, se generaba el problema indemnizatorio al sobreponerse daño a la salud y daño a la autodeterminación. Lo anterior,

${ }^{23}$ Corte cost., 23 de diciembre de 2008, $\mathrm{N}^{\circ} 438$, in Foro Italiano, $\mathrm{N}^{\circ} 5$, parte I, Bologna 2009, c., p. 1328, comentada por Angelo Riccio, "Consenso informato e dissenso fra diritto penale e diritto civile", in Contratto e impresa, No 3, Padova, 2009, pp. 552-579.

pues, luego de haber insistido sobre la relevancia autónoma del derecho del paciente a elegir de someterse o no a un determinado tratamiento sanitario, se adscribía al médico responsable de la conducta omisiva el perjuicio a la salud causado por la intervención aun correctamente realizada. Como se observa, el reparo relativo a la afirmada autonomía del derecho de autodeterminación surge toda vez que se condiciona la pretensión indemnizatoria a la presencia de una lesión a la salud ${ }^{24}$.

Ahora bien, la sentencia de la Casación insiste en que debe distinguirse en modo neto entre el perjuicio a la salud y la lesión del derecho del asistido a ser informado en relación con el tratamiento. En apoyo, el pronunciamiento señala que aun existiendo consentimiento informado se configura responsabilidad por lesión a la salud si la prestación médica es realizada en forma inadecuada y, viceversa, la lesión del derecho de autodeterminación no comporta necesariamente lesión a la salud, como acaece cuando falta el consentimiento, pero la intervención produce un resultado positivo.

"En el primer caso el consentimiento prestado por el paciente es irrelevante, pues la lesión de la salud se asocia causalmente a la conducta culposa del médico en la ejecución de la operación terapéutica, cumplida sin exactitud luego

\footnotetext{
${ }^{24}$ Gorgoni (n. 15), pp. 1.017-1.018.
} 
del diagnóstico. En el segundo, la falta de consentimiento puede asumir importancia a fines indemnizatorios, aunque no exista lesión a la salud o cuando la lesión a la salud no se encuentre causalmente conectada a la lesión del derecho al consentimiento informado, toda vez que se configuren consecuencias perjudiciales (de apreciable gravedad) que deriven de la violación del derecho fundamental de la autodeterminación" ${ }^{25}$.

Con todo, la independencia del derecho autodeterminación no se aclara, ya que la Corte justifica la autonomía de ambos derechos describiendo hipótesis donde resulta comprometida la salud. Detengámonos en ellas.

A la Casación le interesa dilucidar el caso en que

"la prestación terapéutica cause perjuicios que el paciente habría alternativamente preferido soportar en el ámbito de las elecciones que sólo él es capaz de realizar".

Para ello, considera inútil referirse a la prevalencia de otros bienes jurídi-

${ }^{25}$ Sobre este punto la Casación tuvo la oportunidad de referirse en un caso de daño patrimonial y moral por omisión de diagnostico de feto mal formado y del consiguiente perjuicio de la posibilidad de la madre de recurrir a la interrupción voluntaria del embarazo. Cfr. Cass., Nº 13 de 2010. camente protegidos como la "vida" o la misma "salud" en relación con los intereses personales del paciente. Así, señala el fallo,

"a título meramente ejemplificador, no podría a priori negarse tutela indemnizatoria a quien haya conscientemente rechazado una transfusión de sangre por ser contraria a la fe religiosa aun cuando se le haya salvado la vida practicándosela, ya que el paciente podría haber preferido no vivir en vez de vivir en el estado posterior a la transfusión" 26 .

Se agrega, asimismo, que no podría excluirse la indemnización del daño moral por el agudo o crónico dolor físico cuando la elección del médico de privilegiar la tutela de la integridad física del paciente o de su misma vida se haya realizado sin su consentimiento generando sufrimientos físicos que el enfermo habría podido elegir no soportar. Sobre la base de tales consideraciones, la Corte concluye:

"en el caso de la sola violación del derecho de autodeterminación, incluso sin correlativa lesión del derecho a la salud relacionable a ella por haber sido la intervención terapéutica

${ }^{26}$ Es el caso, de común ocurrencia, que afecta a quienes profesando la religión de Testigos de Jehová, rechazan todo tipo de transfusiones de derivados sanguíneos. 
necesaria y correctamente realizada, puede existir un espacio resarcitorio; mientras que para proceder a la indemnización del daño por lesión a la salud por las previsibles consecuencias del acto terapéutico necesario y correctamente ejecutado secundum legem artis, pero sin la preventiva información del paciente sobre sus posibles efectos perjudiciales (...), se requiere necesariamente la demostración que el paciente habría rechazado la intervención si hubiese sido adecuadamente informado" ${ }^{27}$.

Los casos que sirven de apoyo a la argumentación relativa a la indepennación comprometen necesariamente el derecho a la salud y, por lo mismo, no pueden sino generar perplejidad sobre la autonomía proyectada por la Casación ${ }^{28}$. No obstante, yendo más allá de la idealización del pronunciamiento conviene precisar que en la práctica resulta imposible diferenciar ambos derechos, dado que en el

${ }^{27}$ Este criterio ha sido sostenido por un considerable sector de la doctrina italiana. Cfr. Riccio (n. 23); Giovanni FACCI, "Il dovere di informazione del sanitario", in Nuova giur. civ. comm., $\mathrm{N}^{\circ} 12$, Padova, 2006, pp. 617635; Alice Pinna, "Autodeterminazione e consenso: da regola per i trattamenti sanitari a principio generale", in Contratto e impressa, No 3, Padova, 2006, p. 589; Gianni Gennari, "Il consenso informato come espressione di libertà", in Responsabilità Civile e Previdenza, No 10, Milano, 2007, p. 2.140.

${ }^{28}$ Gorgoni (n. 15), p. 1.018.

ámbito clínico el consentimiento se presenta como un mero instrumento de salvaguarda de la salud y de la integridad personal, careciendo, por tanto, de toda relevancia en cuanto fin en sí mismo. Ello es evidente en el caso en examen, donde no resulta sacrificada la autodeterminación en forma abstracta, sino una determinación relativa al propio cuerpo, a la propia existencia y por lo ello indisolublemente ligada a la salud del individuo.

Sobre la base de la argumentación avanzada, el médico responde de la lesión al derecho de la autodeterminación del paciente toda vez que no obtenga su consentimiento informado. Pero existe un límite: el perjuicio autónomo en cuestión, asumiendo una naturaleza no patrimonial, es indemnizable en manera proporcional a la ofensa, es decir,

"el derecho debe ser afectado más allá de un cierto mínimo nivel de tolerabilidad que corresponderá al juez determinar considerando el principio de solidariedad y tolerancia y el parámetro estatuido por la conciencia social en un determinado momento histórico" ${ }^{29}$.

${ }^{29}$ Una breve apreciación relativa a la noción jurisprudencial de daño no patrimonial en el Derecho italiano se torna necesaria. Conforme a lo dispuesto por el art. 2059 del CC: "el daño no patrimonial deber ser resarcido sólo en los casos determinados por la ley". Tal disposición ha sido objeto de una reciente interpretación expansiva en la trascendente decisión del 11 de noviembre de 
De esta forma, la turbación que resulta de las consecuencias verificadas y

2008 No 26972 (de contenido idéntico a otras tres sentencias depositadas contextualmente) de las Sezioni Unite de la Corte Suprema de Casación. El fallo ha reexaminado con profundidad los presupuestos y el contenido de la noción de "daño no patrimonial" de Código Civil. Ratificando que el daño no patrimonial es indemnizable sólo en los casos previstos por la ley, el pronunciamiento ha señalado que tales casos pueden dividirse en dos grupos: las hipótesis en las que la indemnización se encuentra prevista en modo expreso (por ejemplo, en el caso en que el hecho ilícito comporte un delito); y aquellas en que la indemnización del daño, aun no siendo expresamente previsto por una ley ad hoc, deba ser admitida sobre la base de una interpretación "constitucionalmente orientada" del art. 2059 del $C C$, esto es, por haber el hecho ilícito vulnerado en modo grave un derecho de la persona tutelado en modo expreso por la Constitución. La decisión examina, además, el contenido de la noción de daño no patrimonial, disponiendo que éste constituye una categoría amplia y omnicomprensiva, dentro de la cual no es posible divisar subcategorías. Por consiguiente, para la Casación no resulta conforme a derecho distinguir el llamado "daño moral subjetivo" (entendido como un sufrimiento síquico transitorio), de otros daños no patrimoniales: el sufrimiento moral no es más que uno de los múltiples aspectos que el juez debe apreciar en la liquidación del único y unitario daño no patrimonial, no constituyendo entonces un prejuicio diverso e independiente. De este principio se extrae la máxima relativa a la inadmisibilidad del daño "existencial" en el ordenamiento jurídico italiano. Una perdida de tal tipo, causada por un hecho ilícito lesivo de un derecho de la persona garantizado constitucionalmente, no constituye otra cosa que un "daño no patrimonial", indemnizable según lo dispuesto por el art. 2059 del $C C$, no pudiendo entonces ser liquidado en sede separada por el sólo hecho de haber sido denominado diversamente. Al contrario, no imaginadas como posibles representa el daño no patrimonial que en la mayoría de los casos acarrea la violación de la obligación de informar al paciente. En este campo, deben ser remediadas las consecuencias negativas que el enfermo habría evitado sufrir (prefiriendo, por ejemplo, afrontar perjuicios de otro tipo) y las consecuencias inesperadas, porque no previamente advertidas y, por ende, de difícil aprobación. Para la Casación, todo lo anterior debe resarcirse en forma proporcional a la gravedad de la ofensa y atendiendo los límites establecidos por las sentencias de la Secciones Unidas de 11 de noviembre de $2008^{30}$.

$\mathrm{Si}$, además, de ello, la infracción del deber de informar produce consecuencias perjudiciales en el ámbito de la salud por haberse verificado un riesgo imponderable asociado al

cuando un prejuicio de aquellos denominados en doctrina como "existencial" sea causado por conductas que no constituyan lesión a específicos derechos de la persona garantizados constitucionalmente, no será resarcible en vista a la limitación del mismo art. 2059 del $C C$. Lo anterior ha sido remarcado por las Secciones Unidas de la Casación italiana como filtro indemnizatorio negando así el resarcimiento de los daños no patrimoniales llamados bagatellari, es decir, aquéllos de escasa importancia (fútiles o irrisorios) o, bien, de aquéllos causados por conductas carentes del requisito de la gravedad.

${ }^{30}$ Con tales sentencias, cuyo tenor hemos explorado en la nota anterior, se dispone que corresponde al juez valorar la aptitud de los perjuicios no patrimoniales a objeto de conferirles una relevancia constitucional y con ello indemnizatoria. Cfr. Ziviz (n. 15), pp. 791, 794. 
tratamiento médico, dicho evento es indemnizable sólo si el enfermo, debidamente informado por el médico, lo hubiera rechazado. Sobre este punto, el pronunciamiento dispone que incumbe al paciente probar el hipotético rechazo de la intervención. Para arribar a tal conclusión la Corte expone cuatro argumentos:

a) porque la prueba del nexo causal entre el incumplimiento y el daño corresponde a la parte que lo alega y que pretende por tal motivo la indemnización;

b) el hecho positivo a probar es el rechazo que habría sido opuesto por el paciente al médico;

c) porque se trata de establecer en que sentido se habría orientado la elección subjetiva del paciente, por lo que el criterio de distribución de la carga probatoria en función de la "cercanía" del hecho a probar permite arribar a tal conclusión y

d) porque la elección del asistido de discrepar de la valoración de oportunidad del tratamiento indicado por el médico (rechazándolo) es una eventualidad contraria a lo que normalmente ocurre.

\section{Consideraciones CONClusivas}

La novedad de la flamante decisión de la Casación italiana estriba en el haber conferido un espacio indemnizatorio autónomo a la violación del derecho a la autodeterminación, distinguiendo al efecto entre el bien jurídico salud (o vida) y el derecho a la autonomía decisional. El espacio adjudicado al derecho a la autodeterminación resulta innegable. La Corte entiende que el derecho a ser informado constituye un principio fundamental del ciudadano, y como tal, acreedor de una tutela independiente respecto a otros bienes jurídicos. Junto a ello, debe apreciarse que el eje central de la cuestión sometida a examen es la negación del derecho del paciente a determinar su propio destino frente a una enfermedad. No se trata, por consiguiente, de la privación de una simple facultad de elección, sino de una determinación relativa al propio cuerpo, en cuanto indispensable para ser o no ser o para ser en cierto modo u otro ${ }^{31}$. En este contexto, el derecho a la autodeterminación tutela intereses diversos a la salud en la medida que se refieran al ámbito de las decisiones personales y del como curarse, razón que explica la nítida separación -a nivel abstracto- entre la autodeterminación personal (en cuanto tutela de la dignidad humana) y el discurso referente a la salud y a su protección.

Se tendrá presente, además, que la posibilidad indemnizatoria entreabierta por la Casación debe ser mesurada y contextualizada, de modo de evitar el ensanche de la tutela a casos donde la información sea fin en sí misma, es decir, cuando de la intervención no consentida no deriven

${ }^{31}$ Graziadei, “Il consenzo...” n. 6. 
perjuicios o cuando ellos generen efectos de gravedad mínima en el ámbito de las elecciones personales o de los intereses del paciente. Así, no basta invocar la injusta violación del derecho de autodeterminación, en concreto, es necesario demostrar que la infracción al deber de información ha lesionado el derecho de elegir a no someterse a una intervención o a someterse a una intervención diversa de la realizada y que de ello han derivado perjuicios relevantes en el ámbito de los intereses protegidos por la ley. Interesa, por lo tanto, destacar que la violación del derecho a la autodeterminación dará lugar a la pretensión resarcitoria allí donde se pruebe que ella es el antecedente causal de elecciones (o de elecciones omisas) que generen consecuencias perjudiciales para el interesado ${ }^{32}$. En vista a ello, la Casación ha sido cautelosa en reenviar al filtro indemnizatorio establecido por las sentencias de las Secciones Unidas de 2008: la omisión del deber de información ha de ser reparada en forma proporcional al perjuicio sufrido en el plano de las decisiones personales atendiendo a la apreciación discrecional del juez de instancia.

La Corte ha aceptado la existencia de un daño moral autónomo en la lesión del derecho a la autodeterminación independientemente del perjuicio a la salud originado por un mismo evento. Sin embargo, la práctica nos demuestra la imposibilidad de un tratamiento jurídico

${ }^{32}$ Gorgoni (n. 15), pp. 1.021-1.022, 1.024. del todo disociado, puesto que el consentimiento informado no sólo representa uno de los vehículos a través del cual se concretizan los derechos a la salud y a la autodeterminación sino que, además, encarna la tutela de los diversos aspectos de la personalidad, siempre vinculados al ámbito de la salud del individuo. Ello es evidente en el caso estudiado: la lesión de la salud derivada de la extirpación lex artis del cristalino se conecta causalmente a la conducta omisiva del médico de intervenir con la ausencia del consentimiento del interesado, sacrificando su derecho a la autodeterminación. El fallo revela un gran avance en un terreno carente de normativa legal expresa. La jurisprudencia italiana ha sabido moverse con originalidad en un área frágil, de compleja demarcación y aún perfectible.

\section{BibliografíA}

Annas, George J., "Globalized Clinical Trials and Informed Consent", in The New England Journal of Medicine, $\mathrm{N}^{\mathrm{O}}$ 360, Waltham, MA, 2009.

BalduzZi, Renato y Davide PARIS, "Corte costituzionale e consenso informato tra diritti fondamentali e ripartizione delle competenze legislative", in Giurisprudenza Costituzionale, $\mathrm{N}^{\mathrm{o}}$ 6, Milano, 2008.

Cacace, Simona, "Informazione, consenso e rifiuto delle cure", in Giovanni Comandé (ed.), Diritto privato europeo e diritti fondamentali. Saggi e ricerche, Torino, Giappichelli, 2004. 
Campione, Riccardo, "Trattamento medico eseguito lege artis in difetto di consenso: la svolta delle S.U. penali nella prospettiva civilistica", in La Responsabilità Civile, $\mathrm{N}^{\mathrm{O}}$ 11, Torino, 2009.

Casonato, Carlo, "Consenso e rifiuto delle cure in una recente sentenza della Cassazione", in Quaderni costituzionali, No 3, Bologna, 2008.

De la Maza Gazmuri, Iñigo, "Consentimiento informado y relación de causalidad", en Iñigo DE LA MAZA Gazmuri (comp.), Responsabilidad médica. Cuadernos de Análisis Jurídico, Santiago, Ediciones Universidad Diego Portales, 2010, vol. vi

FACCI, Giovanni, "Il dovere di informazione del sanitario (parte II)", in $L a$ Nuova Giurisprudenza Civile Commentata, No 12, Padova, 2006.

324

FACCI, Giovanni, "Brevi osservazioni in tema di funzione riparatoria della responsabilità civile e violazione del sanitario del dovere di informazione", in Responsabilità Civile e Previdenza, No 2, Milano, 2008.

Ferrando, Gilda, "Consenso informato del paziente e responsabilità del medico. Principi, problemi e linee di tendenza", in Studi in onore di Pietro Rescigno, vol. v, Milano, Giuffrè, 1998.

García Rubio, María Paz, "Incumplimiento del deber de información, relación de causalidad y daño en la responsabilidad civil médica", en Eugenio Llamas Pombo (coord.), Estudios de derecho de obligaciones. Homenaje al profesor Mariano Alonso Pérez, Madrid, La Ley, 2006, tomo I.

Gennari, Gianni, "Il consenso informato come espressione di libertà", in Responsabilità Civile e Previdenza, $\mathrm{N}^{\mathrm{O}}$ 10, Milano, 2007.
Gorgoni, Marinela, "Ancora dubbi sul danno risarcibile a seguito di violazione dell'obbligo di informazione gravante sul sanitario", in Responsabilità Civile e Previdenza, N ${ }^{\circ}$ 5, Milano, 2010.

Graziadei, Michele, "What went wrong? Tort law, personal responsibility, expectations of proper care and compensation", in Helmut KOzIOL y Barbara C. Steininger (eds.), European Tort Law 2008 (Tort and Ensurance Law Yearbook), Wien, Springer, 2009.

Graziadei, Michele, "Il consenzo informato e i sudi limiti", in I Diritti in medicina, a cargo de Leonardo LENTI, Elizabetta Palermo Fabris, Paolo ZatTI, Trattato di biodiritto, dirigido por Stefano Rodotà y Paolo ZATTi, Milano, Giuffrè, 2011

Hondius, Edwoud, "The development of medical liability", en Jhon BELL and David IbBetson (eds.), Comparative studies in the development of the law of torts in Europe, Cambridge, Cambridge University Press, 2010, vol. 3.

Hondius, Edwoud, "Comparative Medical Liability in Europe", in Festschrift für Hans Stoll zum 75. Geburtstag, Tübingen, Mohr Siebeck, 2001.

Mastrolitto, Alessandra, "Consenso informato del paziente e responsabilità' professionale del medico", in Annali della Facoltà di Giurisprudenza di Foggia, Milano, Giuffrè, 2005.

Montanari Vergallo, Gianluca, Il rapporto medico-paziente, Milano, Giuffrè, 2008.

NANNini, Ubaldo, Il consenso al trattamento medico: presupposti teorici e applicazioni giurisprudenziali in Francia in Germania, Milano, Giuffrè, 1989. 
Pinna, Alice, "Autodeterminazione e consenso: da regola per i trattamenti sanitaria principio generale", in Contratto e impressa, $\mathrm{N}^{\mathrm{O}} 3$, Padova, 2006.

Pizarro Wilson, Carlos, "Responsabilidad profesional medica: diagnóstico y perspectivas", en Regímenes especiales de responsabilidad civil, Cuadernos de Análisis Jurídico, Santiago, Ediciones Universidad Diego Portales, 2008, vol. IV.

Riccio, Angelo, "Consenso informato e dissenso fra diritto penale e diritto civile", in Contratto e impresa, $\mathrm{N}^{\mathrm{O}} 3$, Padova, 2009.

Riccio, Angelo, "La violazione dell'autodeterminazione è, dunque, autonomamente risarcibile", in Contratto e impressa, No 2, Padova, 2010.

SAntosuosso, Amadeo (edi., Il consenso informato. Tra giustificazione per il medico e diritto del paziente, Milano, Raffaello Cortina Editore, 1996.
Sargos, Pierre, "Deux arrêts 'historiques' en matière de responsabilité médicale générale et de responsabilité particulière liée au manquement d'un médecin à son devoir d'information", in Recueil Dalloz, No 24, Paris, 2010.

Todeschini, Nicola, "Responsabilità professionale e dovere d'informazione: dal consenso disinformato al dovere contrattuale di informare", in Cosimo LORÉ (ed.), Milano, Giuffré, 2008.

Toscano, Giovanni, Informazione, consenso e responsabilità sanitaria, Milano, Giuffrè, 2006.

Trabucchi, Marco, L'ammalato e il suo medico: successi e limiti di una relazione Bologna, il Mulino, 2009.

ZAтti, Paolo, Maschere del diritto volti della vita, Milano, Giuffrè, 2009.

ZIviz, Patrizia, "I labili confini dell'ingiustizia costituzionalmente qualificata", in Responsabilità Civile e Previdenza, $\mathrm{N}^{\mathrm{O}}$ 4, Padova, 2010. 